\title{
Overexpression of $\mathrm{ACE} 2$ produces antitumor effects via inhibition of angiogenesis and tumor cell invasion in vivo and in vitro
}

\author{
YUN FENG $^{1 *}$, LEI NI $^{1 *}$, HUANYING WAN ${ }^{1}$, LIANG FAN $^{1}$, XIAOCHUN FEI ${ }^{2}$, \\ QINYUN MA ${ }^{3}$, BEILI GAO ${ }^{1}$, YI XIANG ${ }^{1}$, JIAMING CHE ${ }^{4}$ and QINGYUN LI ${ }^{1}$ \\ Departments of ${ }^{1}$ Respiration, ${ }^{2}$ Pathology, and ${ }^{3}$ Center of Molecular Medicine, Shanghai Institute of Endocrinology, \\ State Key Laboratory of Medical Genomics; ${ }^{4}$ Cardiac and Thoracic Surgery, Ruijin Hospital, Shanghai \\ Jiaotong University School of Medicine, 197 Ruijin Road II, Shanghai 200025, P.R. China
}

Received May 27, 2011; Accepted June 28, 2011

DOI: 10.3892/or.2011.1394

\begin{abstract}
Angiotensin II (AngII) is a multifunctional bioactive peptide in the renin-angiotensin system (RAS). Angiotensinconverting enzyme 2 (ACE2) is a newly identified component of RAS. The role of AngII and ACE2 in the metastasis of non-small cell lung cancer (NSCLC) and the effects on matrix metalloproteinases (MMPs) are still unknown. In the present study, the anti-invasive effect and mechanism of ACE2 were investigated in vitro and in vivo. Results of a transwell assay showed that the overexpression of ACE2 reduces the invasive ability of A549 cells in vitro. According to the results of qRT-PCR and Western blot analysis, the inhibitory role of ACE2 was mediated through the down-regulation of MMP-2 and MMP-9. Additionally, we confirmed that the overexpression of ACE2 inhibited cell growth and VEGFa production while simultaneously suppressing ACE and angiotensin II type 1 receptor (AT1R) expression in human lung cancer xenografts. These results suggest that the overexpression of ACE2 may potentially suppress the invasion and angiogenesis of NSCLC.
\end{abstract}

\section{Introduction}

Lung cancer is the most common human neoplasm in both developed and developing countries $(1,2)$. Approximately $40 \%$ of lung cancers are adenocarcinomas, which are the

Correspondence to: Dr Huanying Wan or Dr Qingyun Li, Department of Respiration, Ruijin Hospital, Shanghai Jiaotong University School of Medicine, 197 Ruijin Road II, Shanghai 200025, P.R. China

E-mail: hywan_fy@yahoo.com.cn

E-mail: liqingyun68@yahoo.com.cn

*Contributed equally

Key words: matrix metalloproteinases, angiotensin-converting enzyme 2, non-small cell lung cancer, invasion predominant form in both the US and Asia (3). Most patients with lung adenocarcinoma have advanced disease due to the highly metastatic properties of this cancer, making such patients non-surgical candidates. Thus, the metastatic nature of lung adenocarcinoma has been a major barrier to successful treatment and improved patient outcomes.

The renin-angiotensin system (RAS) is important in regulating cardiovascular homeostasis and blood pressure (4). Angiotensin II (AngII), a biologically active octapeptide in RAS, and its biologic effect are mediated via binding to two subtypes of receptors. The receptor subtypes include type 1 (AT1R) and type 2 (AT2R), both of which belong to the G-protein-coupled receptor superfamily (5). Angiotensinconverting enzyme 2 (ACE2) is a newly identified component of RAS, with $42 \%$ amino acid homology to ACE. ACE2 converts AngII to Ang-(1-7) (6), a peptide with vasodilator and anti-proliferative properties.

Tumor invasion and migration require a complex cascade of events involving a finely tuned interplay between malignant cells and multiple host factors. Excess extracellular matrix (ECM) degradation is one of the hallmarks of tumor invasion and migration (7). Matrix metalloproteinases (MMPs) are a large family of at least 20 zinc-dependent neutral endopeptidases that together can degrade all known components of the ECM. Among the human MMPs, MMP-2 (also named gelatinase-A) and MMP-9 (gelatinase-B) show substrate-specificity toward type IV collagen, the major component of the basement membrane. Expression of these two MMPs is strongly linked to tumor metastasis in various types of human cancer (8).

Emerging data suggest that, in addition to systemically produced angiotensin, the tumor environment contains all RAS components necessary to produce angiotensin locally. Importantly, the local RAS system contributes significantly to tumor angiogenesis and progression (9-11). Studies have shown that ACEI reduces non-small cell lung cancer (NSCLC) growth and angiogenesis $(12,13)$ and that lung metastases are reduced by ACEI and angiotensin II type 1 receptor blocker (ARB), via inhibition of MMP-2 expression in mice bearing Lewis lung carcinoma (14). Gallagher and Tallant (15) demonstrated that Ang-(1-7) inhibit lung tumor growth in vivo and in vitro as 
well as reduce vascular endothelial growth factor expression in human lung cancer xenografts, thereby inhibiting tumor angiogenesis (16). Various in vivo studies strongly suggest that a major role of ACE2 involves the generation of Ang-(1-7) from AngII (17-19). We previously reported that overexpression of ACE2 exhibits a protective effect by inhibiting cell growth and VEGFa production in A549 cells in vitro (20). However, the role of AngII and ACE2 in the migration and invasion of NSCLC and the effects on MMPs are still unknown.

In the present study, AngII stimulated the expression of MMP-2 and MMP-9 in A549 human adenocarcinoma cells. In addition, we hypothesized that the ability of ACE2 to reduce the invasive nature of NSCLC is mediated by the down-regulation of MMP-2 and MMP-9. We confirmed that the overexpression of ACE2 inhibited cell growth and VEGFa production while simultaneously suppressing the expression of other RAS components in human lung cancer xenografts.

\section{Materials and methods}

Retroviral vector construct and transduction. The pcDNA3.1 vector containing human ACE2 cDNA was kindly provided by Dr Paul McCray (University of Iowa, Iowa City, IA). They were ligated into the $B g l \mathrm{II} / \mathrm{XhoI}$ site of the $\mathrm{pMSCV}$ plasmid, which expresses human ACE2. 293T cells were transfected with DNA ( $4 \mu \mathrm{g}$ pMD-gag-pol, $4 \mu \mathrm{g}$ pMD-VSVG and $4 \mu \mathrm{g}$ retroviral vector pMSCV-ACE2 or pMSCV) using the Lipofectamine 2000 reagent (Invitrogen Corp., Carlsbad, CA). The replication retrovirus was collected after $48 \mathrm{~h}$ and used to infect A549 cells using polybrene (Sigma Corp., Cream Ridge, $\mathrm{NJ}$ ) and centrifugation was carried out. Infected cells were selected after receiving $4 \mu \mathrm{g} / \mathrm{ml}$ puromycin for 2 weeks. The resistant clones were isolated by limit dilution and dispatched to new dishes. The obtained cells were subsequently named vector and MSCV-ACE2 cells, respectively.

Tumor growth assays. Six- to eight-week-old BALB/c athymic nude mice (Chinese Academy of Sciences, Shanghai, China) were used. Animal experiments were performed in accordance with the institutional guidelines of the University Committee on the Use and Care of Animals. Each mice was inoculated in the flank with $1 \times 10^{6}$ A549 cells infected with MSCV (n=6) or A549 cells infected with MSCV-ACE2 $(n=6)$. Tumor growth was monitored at 3-day intervals by measuring the tumor diameters using a vernier caliper. Tumor volume was determined based on the following formula: Tumor volume $=$ [(major axis) x (minor axis)2] x 1/2. After a 31-day follow-up period, mice were euthanized, and the tumors were removed. Harvested tumors were cut into 2 pieces, one of which was placed in liquid nitrogen and frozen at $-80^{\circ} \mathrm{C}$ and the other was fixed using $4 \%$ paraformaldehyde and then embedded in paraffin.

Immunohistochemistry. Paraffin-embedded tissue sections $(5 \mu \mathrm{m})$ were deparaffinized, microwaved for $5 \mathrm{~min}$ for antigen retrieval, and then incubated with a monoclonal mouse antihuman antibody against Ki-67 (1:50, clone MIB-1; Dako), goat anti-human antibody against VEGFa (1:200, Santa Cruz Biotechnology, Santa Cruz, CA), MMP-2 (1:200, AF902, $\mathrm{R} \& D)$ and MMP-9 (1:200, AF911; R\&D) overnight at $4^{\circ} \mathrm{C}$.
They were rinsed with TBS and incubated in biotinylated IgG antibody for $90 \mathrm{~min}$ at room temperature (RT). After incubation in streptavidin-HRP (1:300) for $30 \mathrm{~min}$ at RT, the sections were developed with 3,3'diaminobenzidine (DAB) substrate and counterstained with hematoxylin. The scoring of NSCLC samples was performed by a histopathologist, by counting at least 500 tumor cells in 5 different visual fields for each specimen. The intensity of the immunoreactivity (intensity score) was stratified and scored as follows: $1, \leq 25 \%$ of cells exhibited positive staining; $2,26-50 \%$ of cells exhibited positive staining; $3,51-75 \%$ of cells exhibited positive staining; and $4,>75 \%$ of cells exhibited positive staining. An intensity score of $\geq 2$ with at least $50 \%$ of tumor cells staining positive was indicative of patients with high expression; intensity score of $<2$ with $<50 \%$ of tumor cells staining positive was indicative of patients with low expression. The total score for each cellular compartment was obtained by calculating the product of intensity and the percentage of staining.

Quantitation of microvessels. For the measurement of microvessel density (MVD), tumor sections were first deparaffinized, endogenous peroxide production was blocked with $1 \%$ hydrogen peroxidase inhibitor and non-specific protein binding was blocked with $10 \%$ rabbit serum and $2 \%$ bovine serum for $30 \mathrm{~min}$. Sections were then incubated overnight at $4^{\circ} \mathrm{C}$ with the anti-mouse CD31 antibody (Dako, Glostrup, Denmark). Finally, sections were incubated for $30 \mathrm{~min}$ with peroxidaselabeled biotinylated anti-rat antibody at RT. After incubation in streptavidin-HRP (1:300) for $30 \mathrm{~min}$ at RT, sections were developed with DAB substrate and counterstained with hematoxylin. Briefly, the immunostained sections were initially screened at low magnifications (x40 and x100) to identify hot spots, which were the areas of highest neovascularization. Any yellow-brown stained endothelial cell or endothelial cell cluster that was clearly separate from adjacent microvessels, tumor cells, and other connective tissue elements was considered a single, countable microvessel. Within the hot spot area, the stained microvessels were counted in a single high-power (x200) field, and the average vessel count in 3 hot spots was considered the MVD value. All counts were performed by three investigators in a blinded manner.

Cell culture and detection of AngII concentration. A549 lung cancer cells (Cell Bank of Chinese Academic of Science, Shanghai) were maintained in Ham's F12 medium with $10 \%$ FBS, $100 \mathrm{mg} / \mathrm{ml}$ penicillin and $100 \mathrm{U} / \mathrm{ml}$ streptomycin using media and growth reagents from Gibco (Gibco-BRL, Grand Island, NY). Cells were prepared at $37^{\circ} \mathrm{C}$ in $5 \% \mathrm{CO}_{2}$. To measure the influence of different concentrations of AngII or overexpression of ACE2 on MMP production, A549 cells infected with MSCV or MSCV-ACE2 were plated in a 12-well plate. After a $24-\mathrm{h}$ incubation in $10 \%$ FBS, the cells were serum starved for $24 \mathrm{~h}$, and incubated in serum-free medium for $24 \mathrm{~h}$. AngII levels were measured in the supernatants of the A549 cells. After a 24-h incubation with 10\% FBS, A549 cells overexpressing ACE2 and control cells were serum starved for $24 \mathrm{~h}$. Cells were then incubated in serum-free medium for $24 \mathrm{~h}$. The culture media were collected, and AngII levels were measured using radioimmunoassay, carried out at the Ruijin Hypertension Institute Laboratory. 
In vitro cell invasion assay. Cell invasion was evaluated using 24-well Matrigel invasion chambers (Becton-Dickinson, Franklin Lakes, NJ). Cells were suspended in the upper chamber at a density of $4 \times 10^{4}$ cells in $200 \mu \mathrm{l}$ medium with various concentrations of AngII. The lower chamber contained $750 \mu 1$ Ham's F12 supplemented with $10 \%$ FCS as a chemoattractant. After incubation for $16 \mathrm{~h}$, the remaining tumor cells on the upper surface of the filters were removed by wiping with cotton swabs, and invading cells on the lower surface were stained using May-Grūnwald Giemsa. The cells on the lower surface of the filters were counted using a microscope. Data were obtained from three individual experiments in triplicate.

Real-time quantitative reverse transcription analysis. MMP-2 and MMP-9 mRNA expression was examined by real-time quantitative reverse transcription-based polymerase chain reaction (qRT-PCR) in untreated A549 cells and those stimulated with AngII $\left(10^{-7}\right.$ and $\left.10^{-6} \mathrm{~mol} / \mathrm{l}\right)$ for $15 \mathrm{~min}$ in vitro. AT1R, ACE, MMP-2 and MMP-9 mRNA expression was also examined in the MSCV-ACE2 and vector groups, in the A549 nude mouse models. RNA was extracted from cells with TRIzol reagent and treated with DNase (Promega, Madison, WI). Complementary DNA was synthesized using a cDNA synthesis kit (Applied Biosystems, Foster City, CA) according to the manufacturer's instructions. Fluorescence qRT-PCR was performed with the double-stranded DNA dye SYBR Green (PCR Core Reagents; PE Biosystems, Warrington, UK), using the ABI PRISM 7300 system (Applied Biosystems). The SYBR Green assay contained $1 \mu \mathrm{l} 10 \mathrm{X}$ SYBR Green PCR buffer, $0.8 \mu \mathrm{l}$ deoxynucleotide triphosphate (dNTP) mixture, $0.1 \mu 1$ AmpErase UNG (1 U/ $\mu 1), 0.05 \mu 1$ AmpliTaq Gold DNA polymerase $(5 \mathrm{U} / \mu \mathrm{l}), 1.2 \mu \mathrm{l} \mathrm{MgCl}_{2}(25 \mathrm{mM}), 0.1 \mu \mathrm{l}$ forward and reverse primer $(20 \mu \mathrm{M}), 1 \mu \mathrm{l}$ cDNA and $5.65 \mu \mathrm{l}$ double distilled $\mathrm{H}_{2} \mathrm{O}$. PCR was initiated with one cycle at $50^{\circ} \mathrm{C}$ for $2 \mathrm{~min}$ and $95^{\circ} \mathrm{C}$ for $10 \mathrm{~min}$ proceeded by 45 cycles of denaturation at $95^{\circ} \mathrm{C}$ for $30 \mathrm{sec}$, annealing at $60^{\circ} \mathrm{C}$ for $30 \mathrm{sec}$, and extension at $72^{\circ} \mathrm{C}$ for $3 \mathrm{sec}$. All data were analyzed using ABI PRISM SDS 2.0 software (Perkin Elmer, Wellesley, MA). Using the $\Delta \mathrm{Ct}$ method, GAPDH was co-amplified to normalize the amount of RNA added to the reaction, and the data were subjected to cycling threshold analysis. PCR was repeated at least three times. The primers used in this study were as follows: ACE forward 5'-CCGATCTGGCAGAACTTC-3' and reverse 5'-GTGTTCCAGATCGTCCTC-3'; AT1-R forward 5'-ATA TTCCCCCAAAAGCCAAATCC-3' and reverse 5'-TCAACC TCAAAACATGGTGCAG-3'; MMP-2 forward 5'-CATTTG GCGGACTGTGAC-3' and reverse 5'-GGGTGCTGGCTG AGTAGAT-3'; MMP-9 forward 5'-TGCCAGTTTCCATTC ATCTTCC-3' and reverse 5'-CCCATCACCGTCGAGTC AGC-3'; GAPDH forward 5'-ATTGCCGACAGGATGC AGA-3' and reverse 5'-GAGTACTTGCGCTCAGGAGGA-3'.

Western blot analysis. MMP-2 and MMP-9 protein levels in A549 cells were studied after treatment with or without AngII $\left(10^{-7}\right.$ and $\left.10^{-6} \mathrm{~mol} / \mathrm{l}\right)$ for $24 \mathrm{~h}$. Expression of MMP-2 and MMP-9 was also assessed in the A549 cells overexpressing ACE2 and compared to the control cells. After being treated with a protein assay reagent (Bio-Rad Laboratories, Hercules, CA), the soluble protein was separated on $10 \%$ SDS-polyacrylamide gels and transferred to PVDF membranes (Millipore, Billerica,
MA). The MMP-2, MMP-9 and $\beta$-actin monoclonal (1:10,000; Sigma Corp., Cream Ridge, NJ) antibodies were used to detect MMP-2, MMP-9 and $\beta$-actin protein, respectively. The immunoreactive bands were visualized with ECL plus reagent (Amersham Biosciences, Piscataway, NJ).

Analysis of MMP-2 and MMP-9 activity using gelatin zymography. Conditioned medium from an equal number of cells was prepared as described above and separated by $10 \%$ acrylamide gels containing $0.1 \%$ gelatin (Invitrogen). The gels were incubated in $2.5 \%$ Triton X-100 solution at RT with gentle agitation to remove SDS and were subsequently soaked in reaction buffer $(50 \mathrm{mM}$ Tris- $\mathrm{HCl}, \mathrm{pH} 7.5,150 \mathrm{mM} \mathrm{NaCl}$, $10 \mathrm{mM} \mathrm{CaCl}_{2}$, and $0.5 \mathrm{mM} \mathrm{ZnCl}$ ) at $37^{\circ} \mathrm{C}$ overnight. After incubation, the gels were stained for $1 \mathrm{~h}$ with staining solution $(0.1 \%$ Coomassie Brilliant Blue, $30 \%$ methanol and $10 \%$ acetic acid) and destained in the same solution, but without Coomassie Brilliant Blue. Gelatinolytic activity of MMP-2 and MMP-9 was visualized as a clear band against a dark background of stained gelatin.

Statistical analysis. Results are expressed as the means \pm $\mathrm{SD}$ of a number of experiments as indicated. The difference between experimental and control values was assessed by the Independent samples test and ANOVA. $\mathrm{P}<0.05$ was considered to indicate a statistically significant difference.

\section{Results}

AngII enhances invasion and MMP production in A549 lung cancer cells. As shown in Fig. $1 \mathrm{~A}, 10^{-7}$ and $10^{-6} \mathrm{~mol} / 1$ of AngII significantly increased the invasive ability of the treated A549 cells. Analysis of qRT-PCR data of MMP-2 and MMP-9 mRNA, corrected for GAPDH as an internal control, showed that $10^{-7}$ and $10^{-6} \mathrm{~mol} / \mathrm{l}$ of AngII significantly increased expression of MMP-2 and MMP-9 mRNA (Fig. 1B and $\mathrm{C} ; \mathrm{P}<0.05)$. In the Western blot analysis, the expression of MMP-2 and MMP-9 protein in the A549 cells treated with $10^{-7}$ and $10^{-6} \mathrm{~mol} / \mathrm{l}$ was significantly higher than the levels in the control cells (Fig. 1D and E). The gelatin zymography assay demonstrated that active MMP-2 (72 kDa) and MMP-9 (92 kDa) expression was increased in the culture medium of the A549 cells treated with $10^{-6} \mathrm{~mol} / \mathrm{l}$ (Fig. $1 \mathrm{~F}$ and G). AngII caused a modest increase in MMP-2 mRNA and significantly increased MMP-9 mRNA. However, Western blot analysis and gelatin zymography assay showed that MMP-9 protein and the activity level were increased in the AngII-treated A549 cells more significantly than MMP-2.

Overexpression of ACE2 inhibits invasion and MMP production in vitro. We investigated whether the overexpression of ACE2 inhibits tumor invasion and MMP production in A549 lung cancer cells. Infection of A549 cells with MSCV-ACE2 resulted in robust ACE2 expression as determined by Western blot analysis at $72 \mathrm{~h}$. No significant ACE2 protein expression was observed in the A549 cells infected with the vector in a similar manner or in the normal lung tissue used as a positive control (Fig. 2A). The AngII concentration in the supernatants of the A549 cells decreased in the MSCV-ACE2 group as compared to the vector cells (Fig. 2B). The in vitro transwell 
(A)
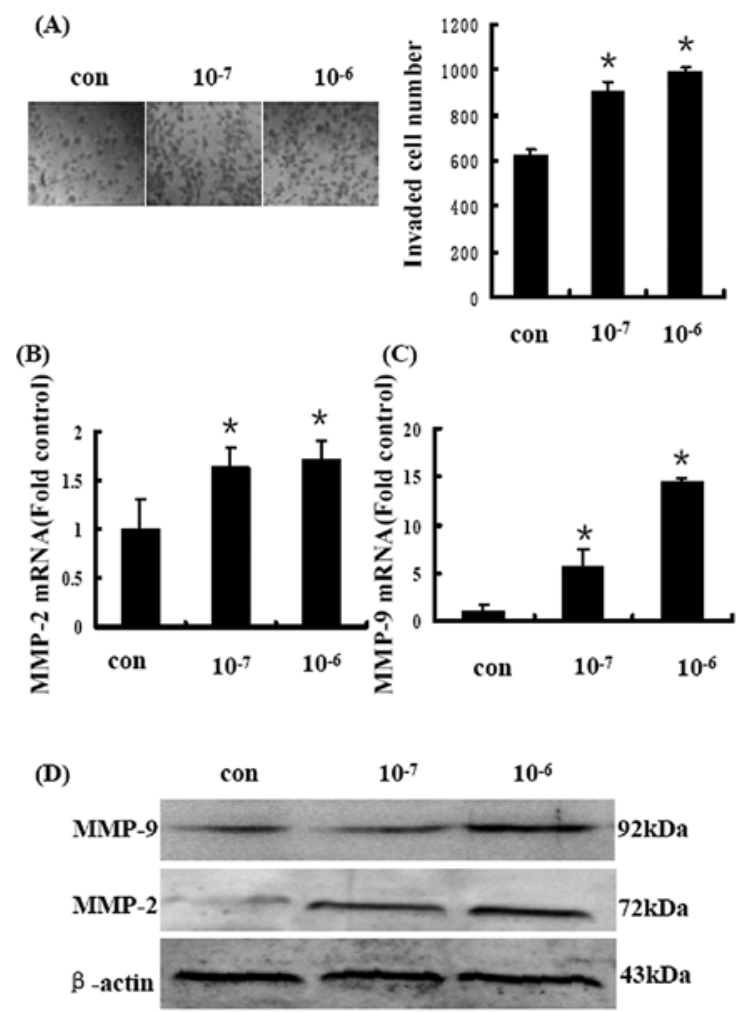

(E)

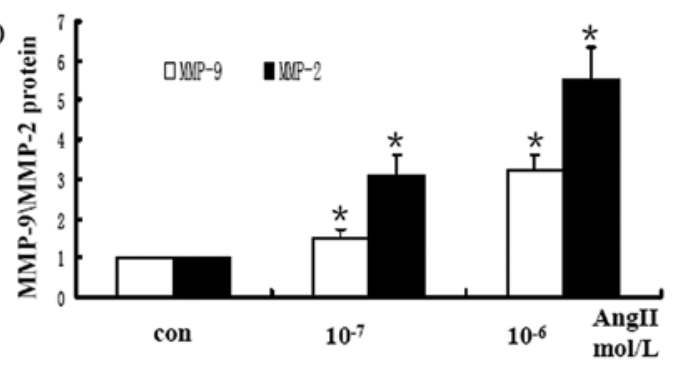

(F)
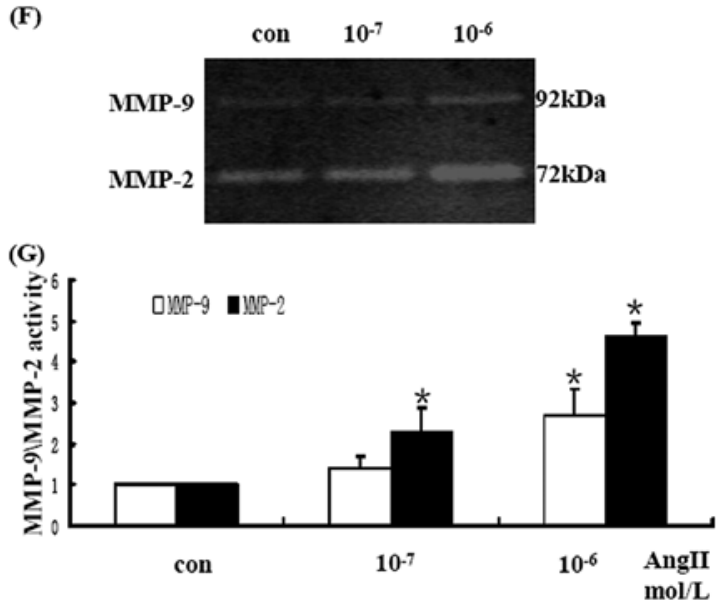

Figure 1. Ang II enhances the invasion and MMP production in A549 lung cancer cells. (A) An in vitro invasion assay was performed using 24-well transwell units coated with Matrigel. The number of invading cells was determined $24 \mathrm{~h}$ after cell seeding. Effects of different concentrations of AngII on production of MMP-2 (B) and MMP-9 (C) mRNA were assessed (means \pm SD, $n=3$ ) ${ }^{*} \mathrm{p}<0.05$. (D) Expression of MMP-2 and MMP-9 protein in cultured A549 cells treated with different concentrations of AngII is shown. (E) Densitometric ratios of MMP-2 and MMP-9 proteins to $\beta$-actin. (F) Zymography assay was performed, and the gelatinolytic activity of active MMP-2 (72 kDa) and MMP-9 (92 kDa) was visualized as clear bands against a dark background of stained gelatin. Values in $(\mathrm{E})$ and $(\mathrm{G})$ (means $\pm \mathrm{SD}$ ) are fold increases. Value of cells without AngII (control) treatment was taken as 1 . All experiments were repeated in triplicate with similar results. ${ }^{*} \mathrm{p}<0.05$ vs. control. assays indicated that the ACE2-overexpressing cells exhibited lower invasive ability than the vector cells (Fig. 2C). Western blot analysis showed that the MMP-2 and MMP-9 protein levels decreased in the A549 cells infected with MSCV-ACE2 compared with expression levels in the vector cells (Fig. 2D and E). Gelatin zymography assays also demonstrated that active MMP-2 (72 kDa) and MMP-9 (92 kDa) levels were decreased in the A549 cells infected with MSCV-ACE2 compared with expression in the cells infected with the vector (Fig. 2F and G).

Overexpression of ACE2 inhibits growth of A549 tumor cells in vivo. To investigate whether the overexpression of ACE2 inhibits pre-established tumor growth in nude mice, all animals were observed and tumors were measured during a 31-day follow-up period. Analysis of Western blot data showed that expression of ACE2 protein in the MSCV-ACE2 group was significantly higher than in the vector group (Fig. 3A). Tumor size in the MSCV-ACE2 group was significantly smaller than that in the vector group (Fig. 3B). The total weight of disseminated tumors in the MSCV-ACE2 group was significantly reduced compared with the vector group (Fig. 3C). Tumor growth curves indicated that the growth in the MSCV-ACE2 group was significantly reduced than that in the vector group (Fig. 3D). These data are in agreement with our previous observations and demonstrated that overexpression of ACE2 significantly inhibited tumor growth in the A549 nude mouse model. In addition, the proliferation-related gene $\mathrm{Ki}-67$ was examined by immunohistochemisty, and the results showed that Ki-67 staining intensity was weaker in the MSCV-ACE2 group than that in the vector group (Fig. 3E).

Overexpression of ACE2 reduces tumor-associated angiogenesis in vivo. The overexpression of ACE2 inhibited VEGFa protein production in vivo, according to immunohistochemical data from A549 tumor tissue xenografts (Fig. 4A). We hypothesized that ACE2 influences neovascularization in tumors. Therefore, we investigated microvessel density (MVD) in tumor sections and found that CD31 (endothelial specific marker)-positive staining was lower in tumors of the MSCV-ACE2 group than in the vector group (Fig. 4B), and MVD was significantly higher in the vector group compared with the MSCV-ACE2 group (Fig. 4C).

Effects of ACE2 overexpression on RAS components and $M M P$ production in vivo. Analysis of qRT-PCR data of ACE, AT1R, MMP-2, and MMP-9 mRNA, corrected for GAPDH as an internal control, showed that the overexpression of ACE2 significantly decreased expression of ACE (Fig. 5A), AT1R (Fig. 5B), MMP-2 (Fig. 5C) and MMP-9 (Fig. 5D) mRNA in the MSCV-ACE2 group. Immunohistochemical analysis showed that the expression of MMP-2 and MMP-9 proteins in the MSCV-ACE2 group was significantly lower than that in the vector group (Fig. 5E and F).

\section{Discussion}

To our knowledge, this study is the first to show that overexpression of ACE2 inhibits tumor invasion, metastasis and MMP production. Several critical findings should be emphasized including the enhancement of invasion of A549 cells by 

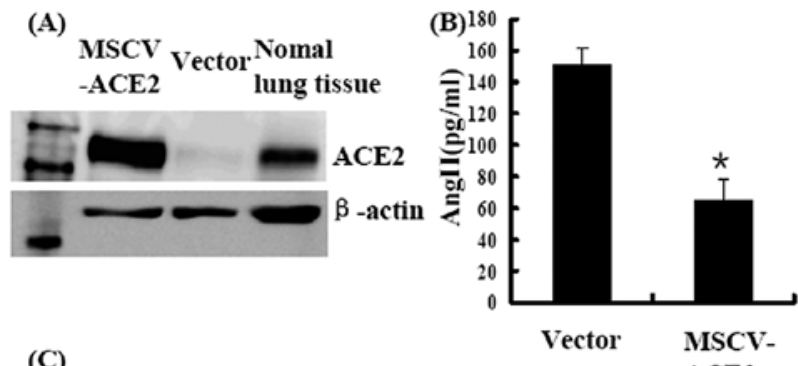

(C)
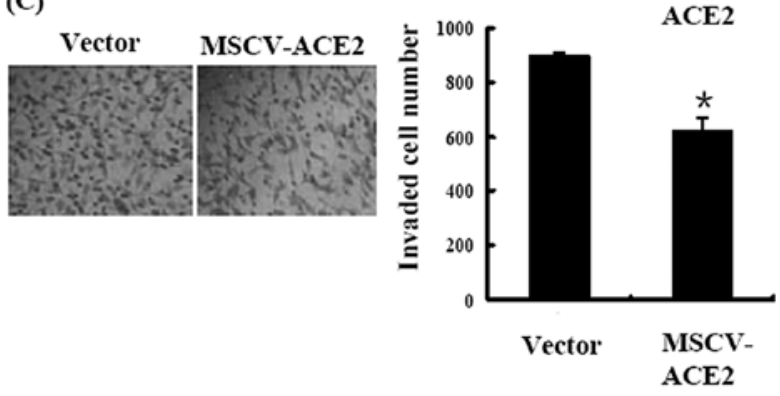

(D)
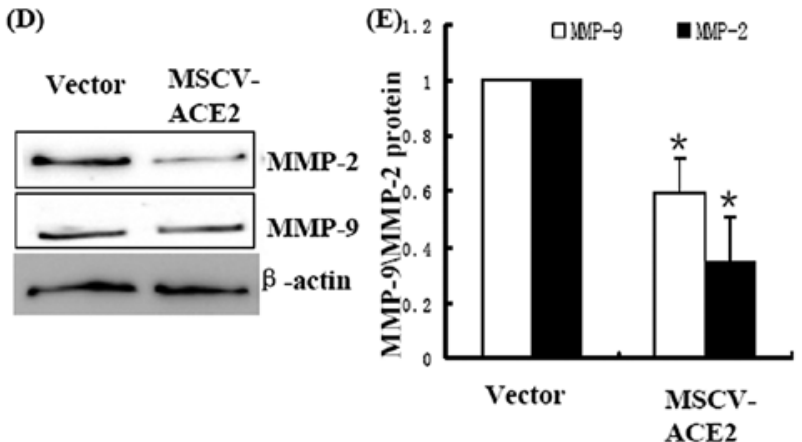

(F)

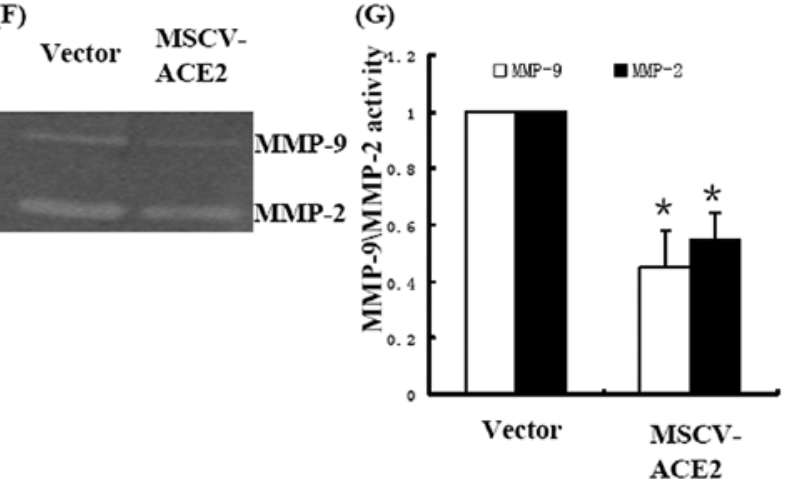

Figure 2. Overexpression of ACE2 inhibits invasion and MMP production in vitro. (A) ACE2 expression increased in the MSCV-ACE2 group compared to the vector group as determined by Western blot analysis. (B) AngII concentration in the supernatants of A549 cells decreased in the MSCV-ACE2 group compared to the vector group. (C) The MSCV-ACE2 group showed significantly decreased invasive ability compared to the vector group in vitro. (D) MMP-2 and MMP-9 protein production was decreased in A549 cells infected with MSCV-ACE2 compared with the vector group as determined by Western blot analysis. (E) Densitometric ratios of MMP-2 and MMP-9 proteins to $\beta$-actin. (F) Zymography assay was performed, and the gelatinolytic activity showed that active MMP-2 (72 kDa) and MMP-9 (92 kDa) were decreased in the MSCV-ACE2 group compared to the vector group in vitro. Values in $(\mathrm{E})$ and $(\mathrm{G})$ (means $\pm \mathrm{SD}$ ) are fold decreases; value for cells of the vector group was taken as 1 . All experiments were repeated in triplicate with similar results. " $\mathrm{p}<0.05$ vs. vector.

AngII in vitro and the involvement of MMP-2 and MMP-9. Additionally, we demonstrated that ACE2 suppresses cancer cell invasion and migration, potentially by decreasing MMP-2
(A)

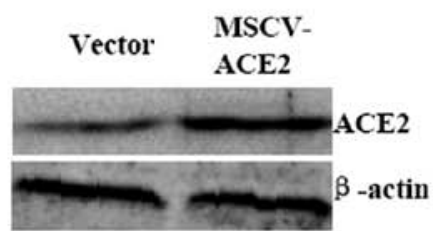

(B)

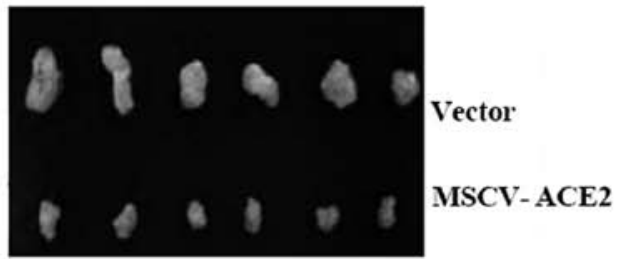

(C)

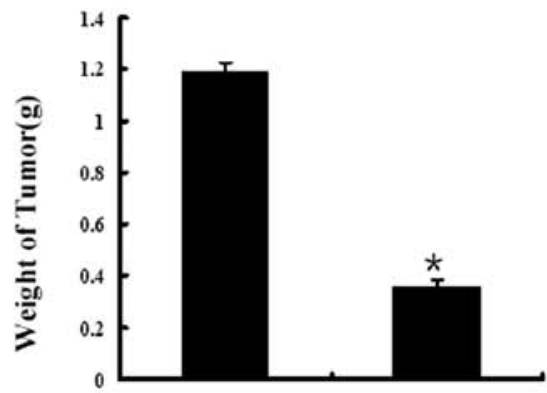

(D)

Vector MSCV-ACE2

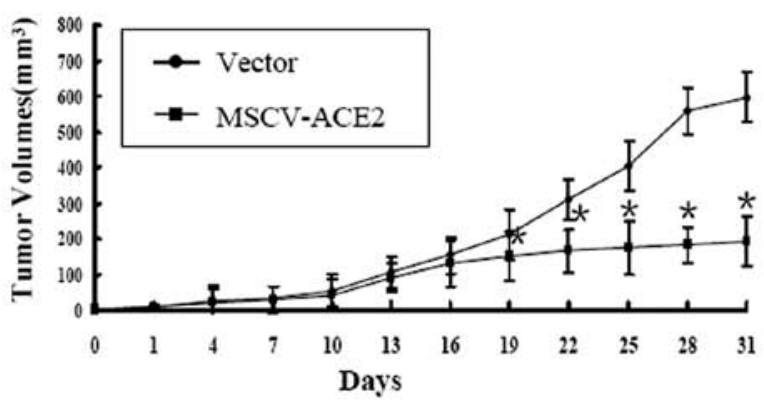

(E)

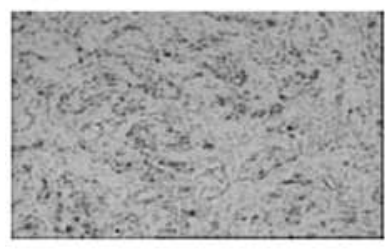

Vector

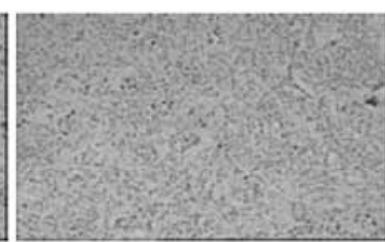

MSCV-ACE2
Figure 3. Overexpression of ACE2 inhibits growth of A549 tumor cells in vivo. Nude mice were xenografted s.c. with human lung A549 cells infected with MSCV or A549 cells infected with MSCV-ACE2 $\left(10^{6}\right.$ cells per animal) for 31 days. Tumors were removed for qRT-PCR and Western blot analysis (A), and images of the tumor samples from both groups are shown (B). The impact of the overexpression of ACE2 on tumor weight (C) and volume (D) is shown. (E) Ki-67 staining intensity was weaker in the MSCV-ACE2 group than in the vector group by immunohistochemistry analysis. Data points represent the means \pm SD of six mice per group. Statistically significant differences are indicated in (C) for tumor weight and (D) for tumor volume ( $\mathrm{p}<0.05 \mathrm{vs.}$ control).

and MMP-9 activity. These data confirm our previous in vivo study in which we revealed that the overexpression of ACE2 inhibits the growth of A549 tumor cells and reduces tumor- 
(A)
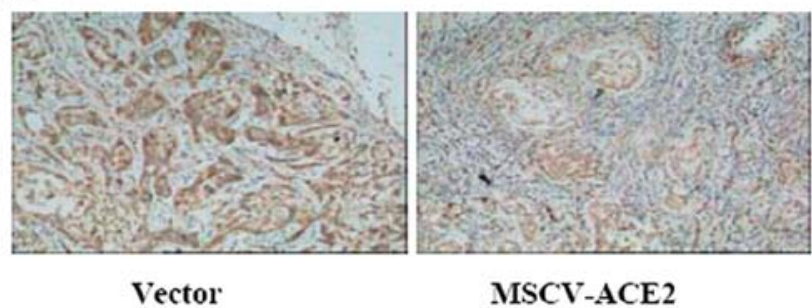

(B)

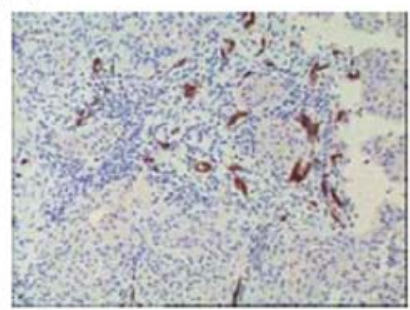

Vector

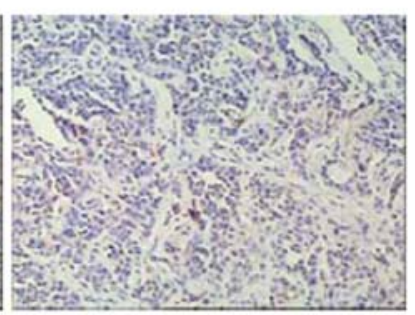

MSCV-ACE2

(C)

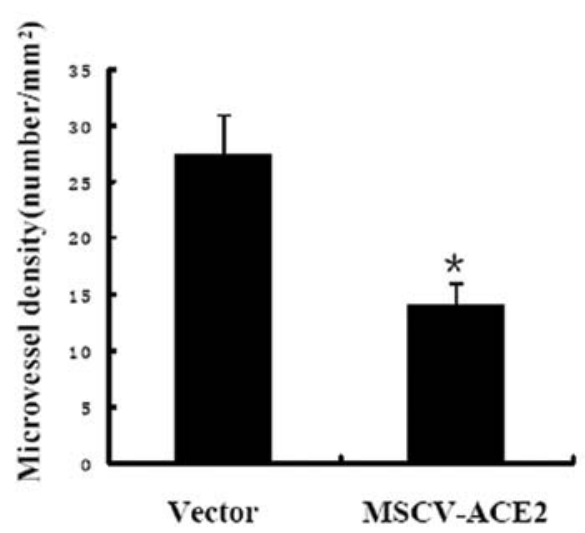

Figure 4. Overexpression of ACE2 reduces tumor-associated angiogenesis in vivo. (A) VEGFa staining intensity was weaker in the MSCV-ACE2 group than in the vector group by immunohistochemistry analysis. (B) Immunohistochemical detection of vascular endothelial cells for CD31 expression. Representative images for the different treatment groups are shown. The positive expression of CD31 is mainly represented as brownishyellow or brownish granules in vascular endothelial cells. (C) Tumor microvessel density (MVD) in the different treatment groups. The MVD in the MSCV-ACE2 group was significantly lower than that in the vector group. ${ }^{*} \mathrm{p}<0.05$.

associated angiogenesis in vivo. These novel findings further support the potential of ACE2 as a new strategy for anti-cancer therapy.

The RAS system increases expression of MMPs and modulates the balance between MMPs and tissue inhibitors of MMPs (TIMPs) in many heart and renal diseases (21-24). Previous cancer studies have demonstrated that AngII augments the migration and invasion of choriocarcinoma cells through the AT1R and induces MMP-2 and MMP-9 expression in gastric cancer cells (25-27). Consistent with these effects of AngII, we showed that treatment with AngII significantly increases the invasive ability of A549 lung cancer cells. qRT-PCR, Western blot analysis, and gelatin zymography analyses showed that AngII induces MMP-2 and MMP-9 expression in A549 cells in vitro.

(A)
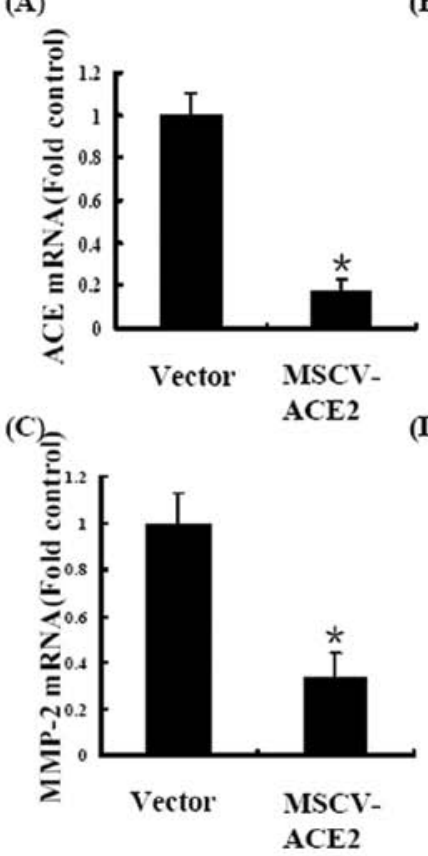

(B)
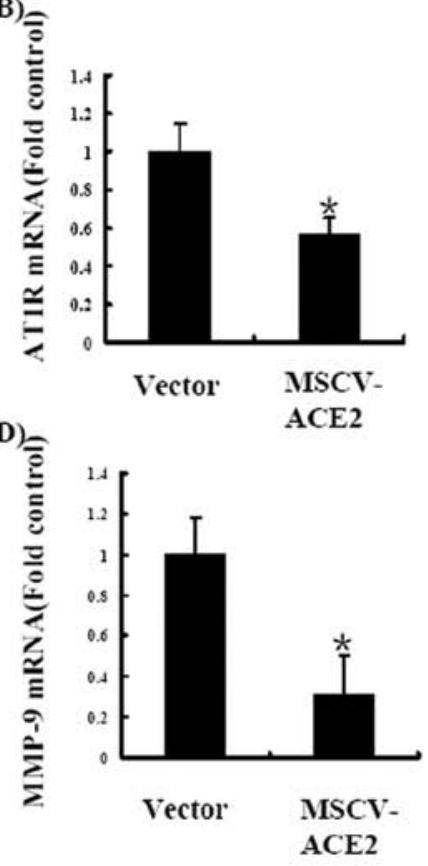

(E)

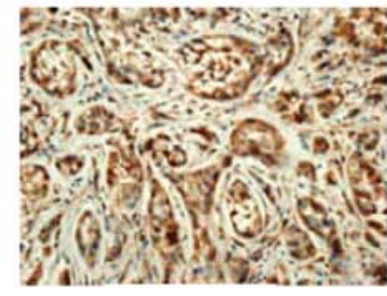

Vector

(F)

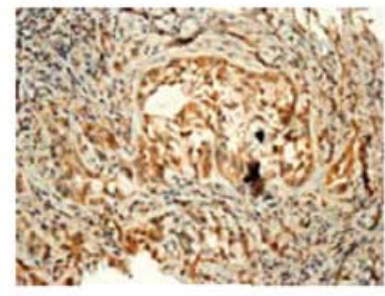

Vector

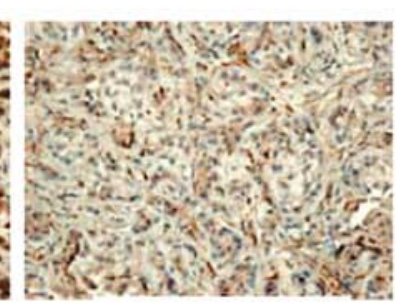

MSCV-ACE2

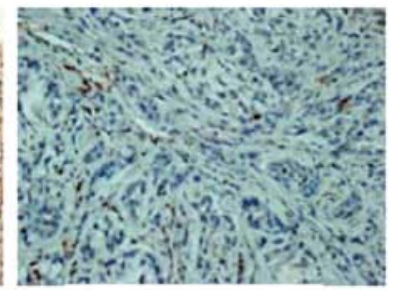

MSCV-ACE2
Figure 5. Effects of ACE2 overexpression on RAS components and MMP productions in vivo. Effects of ACE2 overexpression on production of ACE (A), AT1R (B), MMP-2 (C) and MMP-9 (D) mRNA in an A549 nude mouse model; (means \pm SD, $n=3$ ) ${ }^{*} p<0.05$. Expression of MMP-2 (E) and MMP-9 (F); staining intensity was weaker in the MSCV-ACE2 group than in the vector group as determined by immunohistochemical analysis.

Previous studies have demonstrated moderate ACE2 expression in the lungs of both humans (28) and mice (29), with high levels of ACE2 in the kidney, heart, testis, and small intestine of both species (29-31). In the human lung, immunostaining found that ACE2 was localized to endothelial and smooth muscle cells of large and small blood vessels, as well as type I and II alveolar epithelial cells and bronchial epithelial cells $(32,33)$. In addition to AngI 
and AngII, ACE2 was found to hydrolyze apelin-13, neurotensin-(1-11), dynorphin A-(1-13), $\beta$-casomorphin-(1-7), and ghrelin. Although bradykinin is not hydrolyzed by ACE2 similar to ACE, its metabolite des-Arg (9)-(bradykinin), can be hydrolyzed by ACE2. These peptides have a negative effect on constriction of the myocardium. It was initially hypothesized that disruption of the delicate balance between ACE and ACE2 may result in abnormal blood pressure control. ACE2 may protect against increases in blood pressure and, conversely, ACE2 deficiency could lead to hypertension.

Our previous studies showed that the overexpression of ACE2 inhibits cell growth and VEGFa production in A549 cells (20). In the present study, our data demonstrated that the overexpression of ACE2 inhibits tumor growth and tumorassociated angiogenesis of A549 cells in vivo. We performed immunohistochemical analysis of proliferating cells (Ki-67) in tumor samples from the MSCV-ACE2 group and vector group. Quantification of the Ki-67-positive cells showed a decreased number of dividing tumor cells in the MSCV-ACE2 group compared with the vector group. Our immunohistochemical analysis demonstrated that VEGFa protein and microvessel density were lower in tumors in the MSCV-ACE2 group than that of the vector group, which is notable when one considers that MVD is reported to be a useful prognostic factor of cancer (34).

We assessed whether the overexpression of ACE2 inhibits A549 cell invasion, MMP production and/or change in the expression of RAS components in vitro and in vivo. Many studies have shown that angiotensin-converting enzyme inhibitors (ACE-I) and angiotensin II type 1 receptor blockers (ARB) reduce the invasiveness of gastric cancer cells and human gastric cancer xenografts $(35,36)$. These results correspond with evidence that captopril inhibits human glioma cell migration and invasion via a reduction in MMP activity (37). Consistent with our previous in vitro data, we found that the overexpression of ACE2 decreased ACE and AT1R mRNA in the MSCV-ACE2 group of the A549 nude mouse model in this study. We also found that the overexpression of ACE2 suppressed A549 cell invasion and MMP-2 and MMP-9 activity in vitro and in vivo. Our present study also demonstrated that Ang-(1-7) suppress metastasis and MMP production in A549 cells in vitro (data not shown). Together, these findings reveal that ACE2 inhibits invasiveness and MMP production by AngII in A549 cells through decreased $\mathrm{ACE}$ and AT1R production. Previous studies indicate that the transcription of MMPs is regulated by upstream regulatory sequences, including NF- $\mathrm{B}, \mathrm{AP}-1$ and Ets-1 binding sites $(38,39)$. The PI3K/Akt signaling pathway also plays a crucial role in MMP-2 and MMP-9 gene regulation, cell survival and tumor cell metastasis (40). However, we did not assess the influence of ACE2 on upstream regulatory sequences of MMPs. Further studies are required to evaluate the upstream signaling pathways of MMPs.

Notably, the ratio of ACE/ACE2 is important. Recent research has shown that an imbalance in this ratio leads to various diseases. Many studies have shown that ACE2 appears to be a negative regulator of the RAS and counterbalances the function of ACE. ACE2 converts AngII to Ang-(1-7), which has the opposite function of AngII. We previously found that AngII significantly increased expression of AT1R and decreased expression of ACE2. Overexpression of ACE2 decreases AT1R production in vitro. In the present research we confirmed that overexpression of ACE2 decreased AT1R production in vivo and found that ACE2 overexpression inhibited the expression of ACE. This effect is through the overexpression of ACE2 which decreases AngII production and increases Ang-(1-7) accumulation.

In conclusion, these results suggest the therapeutic potential of ACE2 for controlling tumor progression and metastasis based on its inhibitory effect on the growth and invasion of the A549 adenocarcinoma cancer cell line. However, tumor blood vessels may be constricted and tortuous, thus the effect of ACE2 should be further studied.

\section{Acknowledgements}

This study was financially supported by a grant from the National Natural Science Foundation of China (81071925).

\section{References}

1. Erridge SC, Moller H, Price A and Brewster D: International comparisons of survival from lung cancer: pitfalls and warnings. Nat Clin Pract Oncol 4: 570-577, 2007.

2. McCracken M, Olsen M, Chen MS Jr, Jemal A, Thun M, Cokkinides V, Deapen D and Ward E: Cancer incidence, mortality, and associated risk factors among Asian Americans of Chinese, Filipino, Vietnamese, Korean, and Japanese ethnicities. CA Cancer J Clin 57: 190-205, 2007.

3. Shivapurkar N, Reddy J, Chaudhary PM and Gazdar AF: Apoptosis and lung cancer: a review. J Cell Biochem 88: 885-898, 2003.

4. Brunner HR, Laragh JH, Baer L, Newton MA, Goodwin FT, Krakoff LR, Bard RH and Buhler FR: Essential hypertension: renin and aldosterone, heart attack and stroke. N Engl J Med 286: 441-449, 1972.

5. Fleming I, Kohlstedt K and Busse R: The tissue renin-angiotensin system and intracellular signalling. Curr Opin Nephrol Hypertens 15: 8-13, 2006.

6. Santos RA, Campagnole-Santos MJ and Andrade SP: Angiotensin-(1-7): an update. Regul Pept 91: 45-62, 2009.

7. Huang SC, Ho CT, Lin-Shiau SY and Lin JK: Carnosol inhibits the invasion of B16/F10 mouse melanoma cells by suppressing metalloproteinase-9 through down-regulating nuclear factorkappa B and c-Jun. Biochem Pharmacol 69: 221-232, 2005.

8. Mook OR, Frederiks WM and Van Noorden CJ: The role of gelatinases in colorectal cancer progression and metastasis. Biochim Biophys Acta 1705: 69-89, 2004.

9. Ino K, Shibata K, Kajiyama H, Nawa A, Nomura S and Kikkawa F: Manipulating the angiotensin system - new approaches to the treatment of solid tumours. Expert Opin Biol Ther 6: 243-255, 2006.

10. Vinson GP, Ho MM and Puddefoot JR: The distribution of angiotensin II type 1 receptors, and the tissue renin-angiotensin systems. Mol Med Today 1: 35-39, 2005.

11. Taylor GM, Cook HT, Sheffield EA, Hanson C and Peart WS: Renin in blood vessels in human pulmonary tumors. An immunohistochemical and biochemical study. Am J Pathol 130: 543-551, 1988.

12. Attoub S, Gaben AM, Al-Salam S, Al Sultan MA, John A, Nicholls MG, Mester J and Petroianu G: Captopril as a potential inhibitor of lung tumor growth and metastasis. Ann NY Acad Sci 1138: 65-72, 2008.

13. Imai N, Hashimoto T, Kihara M, Yoshida S, Kawana I, Yazawa T, Kitamura $\mathrm{H}$ and Umemura S: Roles for host and tumor angiotensin II type 1 receptor in tumor growth and tumor-associated angiogenesis. Lab Invest 87: 189-198, 2007.

14. Prontera C, Mariani B, Rossi C, Poggi A and Rotilio D: Inhibition of gelatinase A (MMP-2) by batimastat and captopril reduces tumor growth and lung metastases in mice bearing Lewis lung carcinoma. Int J Cancer 81: 761-766, 1999. 
15. Gallagher PE and Tallant EA: Inhibition of human lung cancer cell growth by angiotensin-(1-7). Carcinogenesis 25: 2045-2052, 2004.

16. Soto-Pantoja DR, Menon J, Gallagher PE and Tallant EA: Angiotensin-(1-7) inhibits tumor angiogenesis in human lung cancer xenografts with a reduction in vascular endothelial growth factor. Mol Cancer Ther 8: 1676-1683, 2009.

17. Zisman LS, Keller RS, Weaver B, Lin Q, Speth R, Bristow MR and Canver CC: Increased angiotensin-(1-7)-forming activity in failing human heart ventricles: evidence for upregulation of the angiotensin-converting enzyme homologue ACE2. Circulation 108: 1707-1712, 2003

18. Li N, Zimpelmann J, Cheng K, Wilkins JA and Burns KD: The role of angiotensin-converting enzyme 2 in the generation of angiotensin 1-7 by rat proximal tubules. Am J Physiol Renal Physiol 288: F353-F362, 2005.

19. Campbell DJ, Zeitz CJ, Esler MD and Horowitz JD: Evidence against a major role for angiotensin converting enzyme-related carboxypeptidase (ACE2) in angiotensin peptide metabolism in the human coronary circulation. J Hypertens 22: 1971-1976, 2004.

20. Feng Y, Wan H, Liu J, Zhang R, Ma Q, Han B, Xiang Y, Che J, Cao H, Fei $X$ and Qiu W: The angiotensin-converting enzyme 2 in tumor growth and tumor-associated angiogenesis in non-small cell lung cancer. Oncol Rep 23: 941-948, 2010.

21. Guo RW, Yang LX, Wang H, Liu B and Wang L: Angiotensin II induces matrix metalloproteinase-9 expression via a nuclear factor-kappaB-dependent pathway in vascular smooth muscle cells. Regul Pept 147: 37-44, 2008.

22. Okada M, Kosaka N, Hoshino Y, Yamawaki H and Hara Y: Effects of captopril and telmisartan on matrix metalloproteinase-2 and -9 expressions and development of left ventricular fibrosis induced by isoprenaline in rats. Biol Pharm Bull 33 $1517-1521,2010$.

23. Yang LX, Liu H, Guo RW, Ye J, Wang XM, Qi F, Guo CM and Liang X: Angiotensin II induces EMMPRIN expression in THP-1 macrophages via the NF-kappaB pathway. Regul Pept 163: 88-95, 2010

24. Zhou L, Xue H, Yuan P, Ni J, Yu C, Huang Y and Lu LM: Angiotensin AT1 receptor activation mediates high glucoseinduced epithelial-mesenchymal transition in renal proximal tubular cells. Clin Exp Pharmacol Physiol 37: e152-e157, 2010.

25. Ishimatsu S, Itakura A, Okada M, Kotani T, Iwase A, Kajiyama H, Ino $\mathrm{K}$ and Kikkawa F: Angiotensin II augmented migration and invasion of choriocarcinoma cells involves PI3K activation through the AT1 receptor. Placenta 27: 587-591, 2006.

26. Huang W, Yu LF, Zhong J, Qiao MM, Jiang FX, Du F, Tian XL and $\mathrm{Wu}$ YL: Angiotensin II type 1 receptor expression in human gastric cancer and induces MMP2 and MMP9 expression in MKN-28 cells. Dig Dis Sci 53: 163-168, 2008.

27. Huang W, Yu LF, Zhong J, Wu W, Zhu JY, Jiang FX and Wu YL: Stat3 is involved in angiotensin II-induced expression of MMP2 in gastric cancer cells. Dig Dis Sci 54: 2056-2062, 2009.
28. Turner AJ, Tipnis SR, Guy JL, Rice G and Hooper NM: ACEH/ ACE2 is a novel mammalian metallocarboxypeptidase and a homologue of angiotensin-converting enzyme insensitive to ACE inhibitors. Can J Physiol Pharmacol 80: 346-353, 2002.

29. Gembardt F, Sterner-Kock A, Imboden H, Spalteholz M, Reibitz F, Schultheiss HP, Siems WE and Walther T: Organspecific distribution of ACE2 mRNA and correlating peptidase activity in rodents. Peptides 26: 1270-1277, 2005.

30. Donoghue M, Hsieh F, Baronas E, Godbout K, Gosselin M, Stagliano N, Donovan M, Woolf B, Robison K, Jeyaseelan R, Breitbart RE and Acton S: A novel angiotensin-converting enzyme-related carboxypeptidase (ACE2) converts angiotensin I to angiotensin 1-9. Circ Res 87: E1-E9, 2000.

31. Tipnis SR, Hooper NM, Hyde R, Karran E, Christie G and Turner AJ: A human homolog of angiotensin-converting enzyme. Cloning and functional expression as a captopril-insensitive carboxypeptidase. J Biol Chem 275: 33238-33243, 2000.

32. Hamming I, Timens W, Bulthuis ML, Lely AT, Navis GJ and van Goor H: Tissue distribution of ACE2 protein, the functional receptor for SARS coronavirus. A first step in understanding SARS pathogenesis. J Pathol 203: 631-637, 2004.

33. Ren X, Glende J, Al-Falah M, de Vries V, SchwegmannWessels C, Qu X, Tan L, Tschernig T, Deng H, Naim HY and Herrler G: Analysis of ACE2 in polarized epithelial cells: surface expression and function as receptor for severe acute respiratory syndrome-associated coronavirus. J Gen Virol 87: 1691-1695, 2006.

34. Offersen BV, Borre M and Overgaard J: Quantification of angiogenesis as a prognostic marker in human carcinomas: a critical evaluation of histopathological methods for estimation of vascular density. Eur J Cancer 39: 881-890, 2003.

35. Carl-McGrath S, Ebert MP, Lendeckel U and Rocken C: Expression of the local angiotensin II system in gastric cancer may facilitate lymphatic invasion and nodal spread. Cancer Biol Ther 6: 1218-1226, 2007.

36. Wang L, Cai SR, Zhang CH, He YL, Zhan WH, Wu H and Peng JJ: Effects of angiotensin-converting enzyme inhibitors and angiotensin II type 1 receptor blockers on lymphangiogenesis of gastric cancer in a nude mouse model. Chin Med J (Engl) 121: 2167-2171, 2008

37. Nakagawa T, Kubota T, Kabuto $M$ and Kodera T: Captopril inhibits glioma cell invasion in vitro: involvement of matrix metalloproteinases. Anticancer Res 15: 1985-1989, 1995.

38. Rothhammer T, Hahne JC, Florin A, Poser I, Soncin F, Wernert N and Bosserhoff AK: The Ets-1 transcription factor is involved in the development and invasion of malignant melanoma. Cell Mol Life Sci 61: 118-128, 2004.

39. Sliva D: Signaling pathways responsible for cancer cell invasion as targets for cancer therapy. Curr Cancer Drug Targets 4: 327-336, 2004.

40. Kim D, Kim S, Koh H, Yoon SO, Chung AS, Cho KS and Chung J: Akt/PKB promotes cancer cell invasion via increased motility and metalloproteinase production. FASEB J 15: 1953-1962, 2001. 